\title{
A case of duodenal adenocarcinoma masquerading as acute cholecystitis and biliary pancreatitis
}

Karim Elghawy, Mohamed A Mohamed, Adel Elmoghrabi, Michael McCann, Qazi Azher, Terry Krznarich, Donald Scholten

Hurley Medical Center, One Hurley Plaza - 7W Trauma Services, Flint, MI, United States

Received: February 23, 2016

DOI: $10.5430 /$ css.v2n2p34
Accepted: March 3, 2016

URL: http://dx.doi.org/10.5430/css.v2n2p34

\begin{abstract}
Background: Small intestinal tumors are rare accounting for less than 5\% of all gastrointestinal (GI) tumors. Primary duodenal carcinoma is very rare among GI tumors and usually presents with non-specific signs and symptoms rendering it difficult for early diagnosis. Importance of early diagnosis arises from the fact that the only curative treatment is radical surgical resection before metastasis. Whipple's procedure remains the most accepted surgical intervention for resectable tumors.

Case presentation: An 82-year-old female presented to the emergency department with a one-day history of epigastric pain and nausea without vomiting. Abdominal examination revealed tenderness in the epigastrium and right upper quadrant. Abdominal ultrasound and laboratory tests were consistent with acute cholecystitis and biliary pancreatitis. She underwent laparoscopic cholecystectomy and intra-operative cholangiogram which revealed a dilated common bile duct with questionable cholelithiasis. Post-operative computed tomography (CT) scan revealed duodenal thickening at the periampullary region suggesting a mass without evidence of metastasis. Esophagogastroduodenoscopy (EGD) confirmed a periampullary mass. Histopathological examination of biopsied tissue revealed moderately differentiated adenocarcinoma. The patient underwent pancreaticoduodenectomy (Whipple's procedure) and had a long, complicated post-operative course and eventually died.

Conclusions: Duodenal adenocarcinoma (DAC) is rare and may present with concomitant acute cholecystitis and biliary pancreatitis.
\end{abstract}

Key Words: Duodenal, Adenocarcinoma, Periampullary, Rare, Pancreaticoduodenectomy

\section{BACKGROUND}

Although small bowel accounts for $75 \%$ of the total length of the entire intestine, tumors arising from the small intestine are relatively rare accounting for less than $5 \%$ of all gastrointestinal (GI) tract cancers. ${ }^{[1]}$ Duodenal Adenocarcinoma (DAC) is a rare tumor representing $0.3 \%-1 \%$ of all GI tumors and $25 \%-35 \%$ of malignant tumors of the small intestine. ${ }^{[2]}$ The atypical presentation of this tumor delays its diagnosis. High index of suspicion is required for early diag- nosis and prompt treatment. To the best of our knowledge, we report the second case of DAC masked by concomitant acute cholecystitis and the first with concomitant biliary pancreatitis on presentation.

\section{CASe PRESEntation}

An 82-year-old African-American female with a body mass index (BMI) of 21 presented to the emergency department with a one day history of postprandial cramping epigastric

*Correspondence: Mohamed A Mohamed; Email: mmohame4@hurleymc.com; Address: Hurley Medical Center, One Hurley Plaza - 7W Trauma Services, Flint, MI 48439, United States. 
pain that radiated to the right upper quadrant and associated with nausea without vomiting. She had a similar milder episode one week prior to presentation that spontaneously resolved. There was no fever, chills, diarrhea, constipation, bloody stools, change in appetite, or weight loss. Past medical history included multiple comorbidities including gastritis, sick sinus syndrome, transient ischemic attacks (TIAs), and intraductal papilloma of the breast. There was no history of peptic ulcer or gall bladder disease. Past surgical history included pacemaker implantation, total abdominal hysterectomy \& bilateral salphingo-oophorectomy. Family history was noncontributory. There was no history of smoking, alcohol or drug intake.

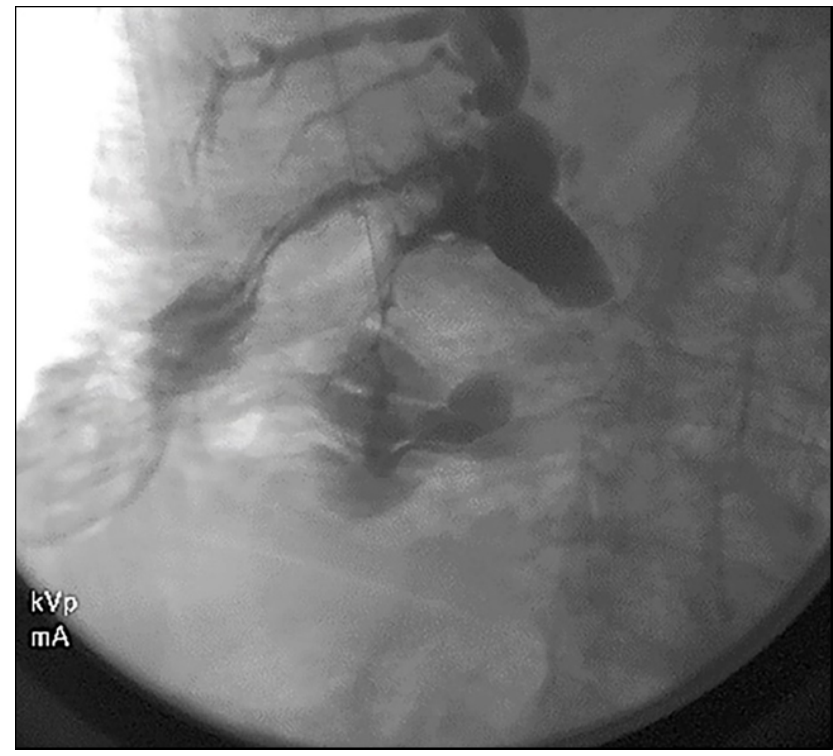

Figure 1. Intra-operative cholangiogram showing dilatation of the common bile duct with a tapering end and flow into the duodenum

On examination, the patient appeared well nourished, with normal vital signs. Abdominal examination revealed epigastric and right upper quadrant tenderness with a positive Murphy's sign. There was no distention, rebound tenderness, guarding or rigidity. Stool guaiac testing was positive. Laboratory investigations revealed a low hemoglobin level $(10.8 \mathrm{~g} / \mathrm{dl})$, mildly elevated direct bilirubin $(0.5 \mathrm{mg} / \mathrm{dl})$ with normal total bilirubin $(0.9 \mathrm{mg} / \mathrm{dl})$, elevated transaminases (AST: $590 \mathrm{U} / \mathrm{L}$, ALT: $253 \mathrm{U} / \mathrm{L}$ ), elevated serum lipase (184 U/L), and an elevated alkaline phosphatase (199 U/L). Abdominal ultrasound revealed a distended gall bladder with wall thickening $(4.6 \mathrm{~mm})$ and dilated common bile duct $(12 \mathrm{~mm})$. No gall stones were detected. Based on her laboratory investigations and ultrasound findings, the picture was suggestive of acute cholecystitis with possible biliary pancreatitis. The patient was admitted and follow-up lab-

Published by Sciedu Press oratory investigations on post-admission day one revealed a remarkable increase in serum lipase (450 U/L) and an elevated serum amylase (296 U/L). There was difficulty in obtaining an esophagogastroduodenoscopy (EGD) or ERCP in a timely fashion. Consequently, she underwent laparoscopic cholecystectomy and an intraoperative cholangiogram that revealed dilated intra and extra hepatic biliary systems with the common bile duct dilated to approximately $1.2 \mathrm{~cm}$ to $1.5 \mathrm{~cm}$ throughout its course. No intraluminal defects were identified, however, there was inconsistent filling of the mid portion of the common bile duct, and a slightly dilated pancreatic duct identified. There was flow ultimately into the duodenum confirming patency. The findings overall were concerning for a periampullary mass (see Figure 1). Pathological examination of the surgical specimen revealed a violet-tan gallbladder measuring $9 \mathrm{~cm} \times 4 \mathrm{~cm}$ containing dark green viscid bile and numerous small black gallstones with an average diameter of $0.1 \mathrm{~cm}$ to $0.3 \mathrm{~cm}$.

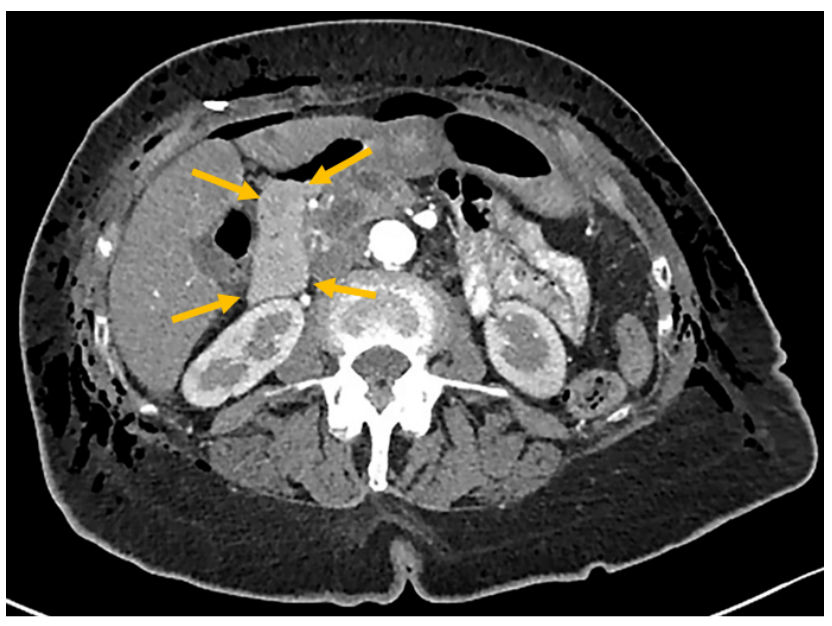

Figure 2. CT of the abdomen with contrast showing circumferential wall thickening at the periampullary region (yellow arrows)

Post-operative computed tomography (CT) of the abdomen and pelvis with contrast revealed circumferential wall thickening at the periampullary region of the duodenum with dilated common bile and pancreatic ducts $(12 \mathrm{~mm} \& 7 \mathrm{~mm}$ respectively) (see Figure 2). No masses or lymphadenopathy were detected. On post admission day five, EGD revealed a periampullary mass. Multiple mass biopsies were taken and were positive for a moderately differentiated adenocarcinoma. Upper GI series to evaluate for gastric outlet obstruction revealed mild narrowing of the second part of the duodenum with mild mucosal irregularity and no duodenal obstruction. Carcinoembryonic antigen (CEA) was normal.

The patient underwent a pancreaticoduodenectomy (Whipple's procedure) and the surgical specimen gross examination 
revealed an ulcerated hemorrhagic tumor mass located within the small intestine measuring $8.7 \mathrm{~cm} \times 6 \mathrm{~cm}$ invading the full thickness of the duodenal wall but not the pancreas. Microscopic examination revealed a histologic grade G2-3 moderately differentiated adenocarcinoma of the duodenum (see Figure 3-A, B \& C). Twenty six lymph nodes were excised and were negative for carcinoma. All the specimen margins were negative. A final diagnosis of primary adenocarcinoma of the duodenum was established (pT2N0).
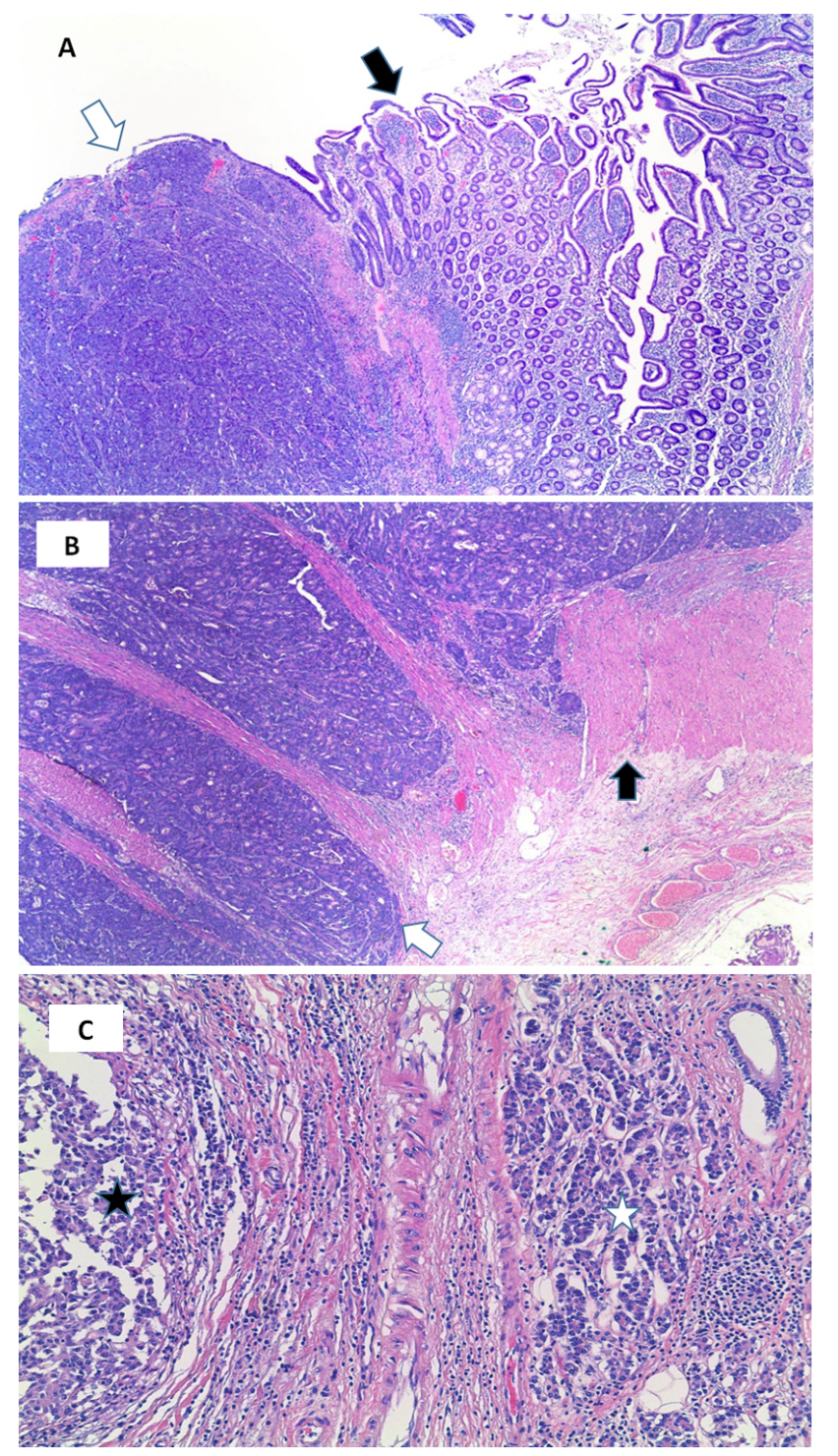

Figure 3. The histologic grade G2-3 moderately differentiated adenocarcinoma of the duodenum A: Black arrow represents relatively normal portion of duodenal mucosa. Portion of adenocarcinoma is indicated by a white arrow (H\&E stain 20×); B: The tumor has invaded through the muscularis properia (white arrow). The muscularis properia is shown with a black arrow $(H \& E, 20 \times)$; C: Invading tumor (black star) is seen in close approximation with pancreatic tissue (white star) $(H \& E, 100 \times)$
The patient had a long and complicated post-operative course. She encountered delayed gastric emptying, sepsis, massive right pleural effusion, and subsequently respiratory failure. Throughout the post-operative course, the patient's condition continued to worsen with evolving sepsis and obtundation. $\mathrm{CT}$ of the brain without contrast revealed a massive right frontal lobe infarct. With the continued worsening, the family finally decided to withdraw care and patient deceased on post-operative day 64.

\section{Discussion}

Small bowel comprises over $75 \%$ of the total length of digestive tract and more than $90 \%$ of its absorptive surface. However, primary small bowel tumors are extremely rare and account for $\leq 5 \%$ of all GI cancers with an estimated global incidence less than one per 100,000 population. ${ }^{[3]}$ In 2015, the estimated number of new cases of small bowel cancer in the United States were 9,410, with a histologic distribution of adenocarcinoma (25\%-50\%), carcinoid (20\%), and less frequently sarcoma and lymphoma. ${ }^{[4]}$ Table 1 describes major published studies and case reports on DAC.

The rarity of small bowel tumors has been explained by many theories including; rapid turnover of small intestinal epithelium preventing accumulation of genetic damage, rapid transit time which limits mucosal cell exposure to carcinogenic agents, lack of bacterial degradation activity from the lower bacterial load, relative dilute alkaline environment, low levels of activating enzymes of precarcinogens, less endogenous reactive oxidative species produced compared to colon, and the abundance of lymphoid tissue in small intestine which increases mucosal immune surveillance. ${ }^{[3,5]}$ Most small bowel adenocarcinomas are sporadic. However, associations with hereditary or inflammatory conditions have been reported. ${ }^{[6,7]}$

Periampullary adenocarcinoma is categorized into four types based on its origin: pancreatic adenocarcinoma, adenocarcinoma of the ampulla of Vater, distal bile duct adenocarcinoma, and DAC which represents the least common type. ${ }^{[2]}$ Yeo et al. identified 242 patients that underwent pancreaticoduodenal resection for periampullary adenocarcinoma from 1970 through 1997. Of those, 62\% were pancreatic primaries, $19 \%$ arose from the ampulla, $12 \%$ were distal bile duct cancers, and $7 \%$ were duodenal in origin. ${ }^{[8]}$

Clinical presentation is usually non-specific and mimics benign conditions. This represents the major obstacle in early diagnosis of DAC. Most common symptoms include abdominal pain, nausea/vomiting, weight loss, GI bleeding, or jaundice. The latter (or a cholecystitis-like picture) may also be a presenting symptom when the DAC is periampullary causing 
obstruction. To the best of our knowledge, this report repre- and the first to present with concomitant biliary pancreatitis. sents the second case of DAC masked by acute cholecystitis

Table 1. Major studies and case reports published on DAC

\begin{tabular}{|c|c|c|c|c|c|c|}
\hline Author & Year & Type of study & Study period & $\begin{array}{l}\text { Aim of study or case } \\
\text { report findings }\end{array}$ & Number of patients & Observations \\
\hline Yeo et al. & 1998 & $\begin{array}{l}\text { Retrospective } \\
\text { review }\end{array}$ & $1970-1992$ & $\begin{array}{l}\text { Compare survival in DAC } \\
\text { with other periampullary } \\
\text { adenocarcinomas after } \\
\text { resection }\end{array}$ & $\begin{array}{l}149 \text { pancreatic } \\
46 \text { ampullary } \\
17 \text { duodenal } \\
30 \text { distal bile ductal }\end{array}$ & $\begin{array}{l}\text { DAC is the least common. DAC has } \\
\text { the most favorable } 5 \text {-year survival rate }\end{array}$ \\
\hline Tocchi et al. & 2003 & $\begin{array}{l}\text { Retrospective } \\
\text { review }\end{array}$ & $1980-2000$ & $\begin{array}{l}\text { Evaluate duodenal } \\
\text { segmentectomy in treating } \\
\text { adenocarcinoma of the } 3^{\text {rd }} \\
\text { and } 4^{\text {th }} \text { duodenal portions }\end{array}$ & $\begin{array}{l}47 \text { DACs of } 3^{\text {rd }} \text { and } \\
4^{\text {th }} \text { portions }\end{array}$ & $\begin{array}{l}\text { Duodenal segmentectomy is preferred } \\
\text { over pancreaticoduodenectomy in } \\
\text { treating adenocarcinoma of } 3^{\text {rd }} \text { and } 4^{\text {th }} \\
\text { duodenal portions }\end{array}$ \\
\hline Akihiro et al. & 2010 & Case report & $\mathrm{n} / \mathrm{a}$ & $\begin{array}{l}\text { Gall bladder perforation } \\
\text { associated with carcinoma } \\
\text { of the duodenal papilla }\end{array}$ & $\mathrm{n} / \mathrm{a}$ & $\mathrm{n} / \mathrm{a}$ \\
\hline $\begin{array}{l}\text { Neoptolemos } \\
\text { et al. }\end{array}$ & 2012 & $\begin{array}{l}\text { Prospective } \\
\text { randomized } \\
\text { controlled trial }\end{array}$ & $2000-2008$ & $\begin{array}{l}\text { Compare adjuvant } \\
\text { chemotherapy with } \\
\text { observation in patients } \\
\text { underwent resection of } \\
\text { periampullary } \\
\text { adenocarcinoma }\end{array}$ & $\begin{array}{l}143 \text { cases } \\
144 \text { controls }\end{array}$ & $\begin{array}{l}\text { Adjuvant chemotherapy was not } \\
\text { associated with significant benefit in } \\
\text { the primary analysis. Multivariate } \\
\text { analysis adjusting for prognostic } \\
\text { variables showed statistically } \\
\text { significant benefit with adjuvant } \\
\text { chemotherapy }\end{array}$ \\
\hline Sahoo et al. & 2013 & Case report & $\mathrm{n} / \mathrm{a}$ & $\begin{array}{l}\text { DAC masked by acute } \\
\text { cholecystitis and peptic } \\
\text { ulcer disease }\end{array}$ & $\mathrm{n} / \mathrm{a}$ & $\mathrm{n} / \mathrm{a}$ \\
\hline Zenali et al. & 2013 & $\begin{array}{l}\text { Retrospective } \\
\text { review }\end{array}$ & $1990-2011$ & $\begin{array}{l}\text { Compare } \\
\text { clinicopathological } \\
\text { features and prognosis of } \\
\text { DAC to AA and PDA in } \\
\text { patients who underwent } \\
\text { resection }\end{array}$ & $\begin{array}{l}68 \text { DACs } \\
92 \text { AAs } \\
126 \text { PDAs }\end{array}$ & $\begin{array}{l}\text { DAC and AA have better prognosis } \\
\text { than PDA. Lymph node metastasis } \\
\text { and AJCC stage are important } \\
\text { prognostic factors }\end{array}$ \\
\hline Plichta et al. & 2014 & $\begin{array}{l}\text { Retrospective } \\
\text { review }\end{array}$ & $2001-2009$ & $\begin{array}{l}\text { Study the association } \\
\text { between survival and } \\
\text { pathologic features of } \\
\text { periampullary tumors }\end{array}$ & $\begin{array}{l}207 \text { periampullary } \\
\text { tumors }\end{array}$ & $\begin{array}{l}\text { Survival within } 1^{\text {st }} \text { year after resection } \\
\text { is strongly associated with lymph } \\
\text { node ratio. Survival within } 3 \text { years is } \\
\text { strongly associated with perineural } \\
\text { invasion and qualitative lymph node } \\
\text { status }\end{array}$ \\
\hline Khan et al. & 2015 & $\begin{array}{l}\text { Retrospective } \\
\text { review }\end{array}$ & $1996-2011$ & $\begin{array}{l}\text { Study prognostic features } \\
\text { and outcomes in SBA } \\
\text { patients }\end{array}$ & 84 SBAs & $\begin{array}{l}\text { Poor histologic differentiation, } \\
\text { abnormal CEA at presentation, and } \\
\text { lymphovascular invasion are } \\
\text { important prognostic factors in early } \\
\text { SBA. Low albumin and abnormal } \\
\text { platelet count are prognostic of worse } \\
\text { overall survival. Patients with } \\
\text { advanced SBA benefit from systemic } \\
\text { chemotherapy }\end{array}$ \\
\hline
\end{tabular}

Note. DAC: duodenal adenocarcinoma; AA: ampullary adenocarcinoma; PDA: pancreatic ductal adenocarcinoma; SBA: small bowel adenocarcinoma; AJCC: American Joint Committee on Cancer; CEA: Carcinoembryonic antigen

In our case, one can argue that cholelithiasis was likely the cause of cholecystitis/pancreatitis, and that the finding of the periampullary tumor was incidental. Although we cannot ascertain that the latter was directly the cause, we believe it was rather a contributing factor. The multiple gall bladder pigment stones found postoperatively were all tiny, and are commonly seen in the elderly. The periampullary tumor may have increased the likelihood for impaction of small passing stones, resulting in the evolvement of cholesystitis/pancreatitis; a clinical picture that eventually revealed a major underlying contributing pathology. One might also argue that in the face of pancreatitis, holding-off on surgical intervention was warranted until at least some resolution of pancreatitis was achieved especially in an elderly with co- 
morbidities. In our case however, a clinical judgment was made for cholecystectomy for fear of rapid deterioration in the face of evolving acute cholecystitis and possibly ascending cholangitis. Thus, the judgement was to intervene on what was initially apparent before deterioration progressed to the inevitable.

In 2013, Sahoo and Gowda reported a case of DAC involving the first and second parts of the duodenum masked by acute cholecystitis and peptic ulcer disease. ${ }^{[2]}$ In 2010 Akihiro et al. reported a case of acute cholecystitis and gall bladder perforation associated with periampullary adenocarcinoma however originating from the ampulla of Vater. ${ }^{[9]}$ The average time between initial presentation and diagnosis has been reported to be seven to ten months. ${ }^{[2]}$ However, improvements in cross-sectional imaging as well as endoscopic and percutaneous interventions have improved the overall diagnostic and staging capabilities. ${ }^{[8]}$

EGD remains the standard screening tool for small bowel tumors. ${ }^{[7]}$ Contrast studies are useful for more distal tumors that may be missed by endoscopy. Advancements in CT and more recently PET scans improved the diagnosis of DAC. Nowadays, CT represents an essential modality for staging and treatment planning of all cases of biopsy-confirmed DAC. Other more recently used modalities include double balloon endoscopy and wireless capsule endoscopy offering the ability to visualize the entire small bowel. The former however, requires significant expertise and is not widely available. Wireless capsule endoscopy is of use in patients with obscure GI bleeding where other investigations have been inconclusive. It is capable of visualizing and characterizing subtle mucosal lesions, however, tissue acquisition is not possible and it is contraindicated in bowel obstruction. ${ }^{[3,5,7]}$

Radical pancreaticoduodenectomy (Whipple's procedure) is the standard curative treatment for these tumors and remains the treatment of choice. Some authors recommend duodenal segmentectomy for tumors in the third and fourth portions of the duodenum. Tocchi et al. preformed a retrospective review on 47 patients with primary adenocarcinoma of the third and fourth portions of the duodenum who underwent segmental duodenal resection. ${ }^{[10]}$ They suggested that this should be the preferred procedure for such patients as their results demonstrated negligible rates of morbidity and mortality while allowing satisfactory marginal clearance and adequate lymphadenectomy. Similar results have been observed in several other cases with up to 5 years of follow-up. ${ }^{[1,12]}$ However, larger studies are needed to compare duodenal segmentectomy to Whipple's procedure for such cases.

The role of adjuvant chemotherapy and radiotherapy is still controversial. Neoptolemos et al. compared 144 patients assigned for observation versus 143 patients that received chemotherapy (fluorouracil plus folinic acid or gemcitabine) after surgical resection of periampullary adenocarcinoma. After adjusting for certain prognostic variables including sex, smoking status, diabetes, performance status, grade of disease, lymph node status, stage and local invasion, their secondary analysis demonstrated a statistically significant survival benefit. ${ }^{[13]}$ Another study that compared quality of life after adjuvant chemotherapy and radiotherapy versus surgery alone in resectable pancreatic and periampullary cancer concluded that combined chemotherapy and radiotherapy improved quality of life over a 24 months period, compared to surgery alone in these patients. ${ }^{[14]}$ Nonetheless, authors agreed that more randomized controlled trials are needed to define the role of adjuvant therapy in treating DAC and periampullary tumors in general.

Inoperable cases may undergo bypass surgery or stenting as a palliation. ${ }^{[15]}$ The 5-year survival rate for curatively resected DAC ranges from $50 \%$ to $60 \% .{ }^{[7]}$ Several prognostic factors were reported in literature including: tumor differentiation, lymph node involvement, resection margins, age of the patient, abnormal CEA at presentation, low albumin, and low platelet count. In a 5-year survival analysis of patients that underwent pancreaticoduodenectomy for periampullary adenocarcinoma, the tumor-specific 5-year survival rates were $15 \%$ for pancreatic, $27 \%$ for distal bile duct, $39 \%$ for ampullary, and 59\% for duodenal tumors. ${ }^{[8]}$ Another study comparing the clinicopathologic features and prognosis of DAC with ampullary adenocarcinoma (AA) and pancreatic ductal adenocarcinoma (PDA), demonstrated that lymph node metastasis and the American Joint Committee on Cancer (AJCC) staging are important prognostic factors. Patients with DAC and AA had less frequent nodal metastasis and better prognosis than those with PDA, and the overall 5-year survival for DAC patients was $55.9 \%$. $^{[6]}$

\section{Conclusions}

DAC is rare. Non-specific clinical presentation delays the diagnosis. Patients may present with concomitant acute cholecystitis and biliary pancreatitis. In such patients, DAC should be considered in the differential diagnosis with high index of suspicion maintained in order to achieve early diagnosis. Pancreaticoduodenectomy (Whipple's procedure) still remains the treatment of choice reported in literature for resectable disease. In our patient, a long and complicated postoperative course ensued resulting in death.

\section{Ethics approval and consent}

Written informed consent was obtained from the patient for publication of this Case report and any accompanying im- 
ages.

\section{Authors' contribution}

KE wrote the initial draft, carried out the literature search and was involved in all aspects of the operation. MM and AE made substantial edits and helped in review of literature. MMc and DS were the surgeons that operated on the patient and revised the manuscript. QA and TK performed the histological analysis and provided histological sections as figures and revised the manuscript. DS supervised the whole operation. All authors read and approved the final manuscript.

\section{Conflicts OF Interest Disclosure}

The authors declare that they have no competing interests.

\section{REFERENCES}

[1] Khan K, Peckitt C, Sclafani F, et al. Prognostic factors and treatment outcomes in patients with Small Bowel Adenocarcinoma (SBA): the Royal Marsden Hospital (RMH) experience. BMC Cancer. 2015; 15 : 15. PMid: 25603878. http://dx.doi.org/10.1186/s12885-0 15-1014-6

[2] Sahoo MR, Gowda MS. Duodenal adenocarcinoma masked by acute cholecystitis and peptic ulcer disease. BMJ Case Rep. 2013; 2013.

[3] Umman P, Adiyodi V, Narayan C. Small bowel adenocarcinoma report of two cases and review of literature. Indian J Surg. 2013; 75(2): 123-7. PMid: 24426406. http://dx.doi.org/10.1007/s 12262-012-0598-1

[4] NCI. small intestine cancer treatment- for health professionals Version (PDQ®). 2015 [updated 04-28-2015; cited 2015 01-05-2016]. Available from: http://www.cancer.gov/types/small-int estine/hp/small-intestine-treatment-pdq\#section/_1

[5] Overman MJ. Rare but real: management of small bowel adenocarcinoma. Am Soc Clin Oncol Educ Book. 2013: 189-93. PMid: 23714497. http://dx.doi.org/10.1200/EdBook_AM.2 013.33.189

[6] Zenali M, Overman MJ, Rashid A, et al. Clinicopathologic features and prognosis of duodenal adenocarcinoma and comparison with ampullary and pancreatic ductal adenocarcinoma. Hum Pathol. 2013; 44(12): 2792-8. PMid: 24139211. http://dx.doi.org/10.1016 /j.humpath.2013.07.030

[7] Lee CC, $\mathrm{Ng} \mathrm{WK}$, Lin KW, et al. Adenocarcinoma of the duodenum. Hong Kong Med J. 2008; 14(1): 67-9. PMid: 18239248.

[8] Yeo CJ, Sohn TA, Cameron JL, et al. Periampullary adenocarcinoma: analysis of 5-year survivors. Ann Surg. 1998; 227(6): 821-31. PMid: 9637545. http://dx.doi.org/10.1097/00000658-199 806000-00005
[9] Hosaka A, Nagayoshi M, Sugizaki K, et al. Gallbladder perforation associated with carcinoma of the duodenal papilla: a case report. World J Surg Oncol. 2010; 8: 41. PMid: 20487525. http: //dx.doi.org/10.1186/1477-7819-8-41

[10] Tocchi A, Mazzoni G, Puma F, et al. Adenocarcinoma of the third and fourth portions of the duodenum: results of surgical treatment. Arch Surg. 2003; 138(1): 80-5. PMid: 12511157. http: //dx.doi.org/10.1001/archsurg.138.1.80

[11] Nakano T, Sugawara K, Hirau K, et al. Primary adenocarcinoma of the fourth portion of the duodenum: "A case report and literature review". Int J Surg Case Rep. 2013; 4(7): 619-22. PMid: 23708691. http://dx.doi.org/10.1016/j.ijscr.2013.04.002

[12] Sista F, Santis GD, Giuliani A, et al. Adenocarcinoma of the third duodenal portion: Case report and review of literature. World J Gastrointest Surg. 2012; 4(1): 23-6. PMid: 22347539. http: //dx.doi.org/10.4240/wjgs.v4.i1.23

[13] Neoptolemos JP, Moore MJ, Cox TF, et al. Effect of adjuvant chemotherapy with fluorouracil plus folinic acid or gemcitabine vs observation on survival in patients with resected periampullary adenocarcinoma: the ESPAC-3 periampullary cancer randomized trial. JAMA. 2012; 308(2): 147-56. PMid: 22782416. http://dx.doi .org/10.1001/jama.2012.7352

[14] Morak MJ, Pek CJ, Kompanje EJ, et al. Quality of life after adjuvant intra-arterial chemotherapy and radiotherapy versus surgery alone in resectable pancreatic and periampullary cancer: a prospective randomized controlled study. Cancer. 2010; 116(4): 830-6. PMid: 20029974. http://dx.doi.org/10.1002/cncr. 24809

[15] Ando T, Ishikawa T, Imamoto E, et al. A case of inoperable duodenal cancer achieving long-term survival after multidisciplinary treatment. Case Rep Gastroenterol. 2012; 6(1): 111-7. PMid: 22761604 http://dx.doi.org/10.1159/000336821 